\title{
HYDROGENATION OF AROMATIC NITRO COMPOUNDS TO AMINES ON NICKEL AND IRON-CONTAINING CATALYSTS
}

\author{
L.R. Sassykova ${ }^{1, \bowtie}$, A.R. Sassykova ${ }^{2}$, Sh. N. Kubekova ${ }^{3}$, A.A. Batyrbayeva ${ }^{1}$, \\ R. N. Azhigulova ${ }^{1}$, Zh. M. Zhaxibayeva ${ }^{4}$, M. A. Kozhaisakova ${ }^{5}$, \\ L. A. Zhusupova ${ }^{6}$, S. Sendilvelan ${ }^{7}$ and O.I. Ponomarenko ${ }^{1}$ \\ ${ }^{1}$ Al-Farabi Kazakh National University, Almaty-050040, Kazakhstan \\ ${ }^{2}$ Almaty College of Economics and Law, Almaty-050004, Kazakhstan \\ ${ }^{3}$ Satbayev University, Kazakh National Research Technical University after K.I. Satpayev, \\ Almaty-050013, Kazakhstan \\ ${ }^{4}$ Abai Kazakh National Pedagogical University, Almaty-050000, Kazakhstan \\ ${ }^{5}$ Almaty Technological University, Almaty-050012, Kazakhstan \\ ${ }^{6}$ Korkyt Ata Kyzylorda State University, Kyzylorda-120000, Kazakhstan \\ ${ }^{7}$ Department of Mechanical Engineering, Dr. M.G.R. Educational and Research Institute, \\ University, Chennai-600095, Tamilnadu, India \\ ${ }^{\square}$ Corresponding Author: larissa.rav@mail.ru
}

\begin{abstract}
A special place among the chemical transformations of nitro compounds is the reduction reaction allowing the production of valuable amines. In this review, the focus is on the discussion of nickel and iron-containing catalysts. Nickel is the most common catalyst for the reduction of various substances, including nitro compounds. Along with Raney nickel different nickel-based catalysts are used: nickel black, $\mathrm{Ni} / \mathrm{Al}_{2} \mathrm{O}_{3}, \mathrm{Ni} / \mathrm{C}, \mathrm{Ni} / \mathrm{kieselguhr}, \mathrm{Ni} / \mathrm{SiO}_{2}$, $\mathrm{Ni} / \mathrm{ZnO}, \mathrm{Ni} / \mathrm{MgO}, \mathrm{Ni}-\mathrm{Cr}_{2} \mathrm{O}_{3} / \mathrm{C}$. Today iron-containing catalysts are successfully used in various processes (FischerTropsch synthesis, Gaber-Bosch, dehydrogenation, dechlorination of organochlorine compounds) and during last years the papers devoted to the application of Fe-containing catalysts for selective catalytic reduction of nitro compounds have been published. The application of catalytic systems based on $\mathrm{Fe}$ and $\mathrm{Fe}_{\mathrm{x}} \mathrm{O}_{\mathrm{y}}$ nanoparticles for implementation of the selective hydrogenation of nitro groups is a promising decision for replacing expensive catalysts prepared of Pt-group metals.
\end{abstract}

Keywords: Liquid-phase Hydrogenation, Aromatic Nitro Compounds, Aromatic Amines, Nickel, Iron.

RASĀYAN J. Chem., Vol. 14, No.2, 2021

\section{INTRODUCTION}

A huge range of amines can be obtained from nitro compounds through the reduction reaction of nitro groups. Amines have wide application in the production of various dyes, drugs, corrosion inhibitors, stabilizers, polyurethanes, antiknock additives for gasoline and motor fuels. ${ }^{1-3}$ Hydrogenation of aromatic nitro compounds is carried out in the liquid or gas phase and in either case, heterogeneous catalysis is used. ${ }^{4-8}$ Many hydrogenation processes go through several intermediate stages and the hydrogenation of aromatic nitro compounds is no exception. Thus, upon the reduction of nitrobenzene in the reaction mixture, a different amount of azobenzene is detected. ${ }^{8}$ Possibly with a lack of hydrogen on the surface of the catalyst, nitrobenzene displaces from the surface primary intermediate products - nitrosobenzene and phenylhydroxylamine, which, interacting with each other, form azobenzene. The increase in pressure increases the concentration of hydrogen on the surface of the catalyst and contributes to the complete reduction of nitrobenzene. With the further development of adverse reactions, hydrogenolysis of the organic compound may occur with the formation of undesirable degradation products. Hydrogenation of substituted nitrobenzenes proceeds by complex series-parallel schemes of chemical transformations. ${ }^{1-3,9} \mathrm{In}$ some cases, inhibition of the reaction by the resulting hydrogenation products is possible. ${ }^{10-21}$ 
RASĀYAN J. Chem.

Vol. 14 | No. 2 |1223-1229| April - June | 2021

There are characteristic types of kinetic curves of the reactions of liquid-phase hydrogenation of various functional groups (Fig.-1). In the case of the high reactivity of reaction intermediates, a hydrogenation mechanism is observed (Fig.-1a). For liquid-phase hydrogenation reactions of substituted nitrobenzenes over nickel catalysts curves of type Fig.-1a and b are the most characteristic. The condensation mechanism of hydrogenation is characterized by extreme dependences of the observed kinetic parameters at high concentrations of the starting materials (Fig.-1b). The kinetic curve in Fig.-1c is a reduction process by the hydrogenation mechanism, accompanied by partial oxidation of the catalyst surface. In this review, the main focus is on the discussion of nickel and iron-containing catalysts.

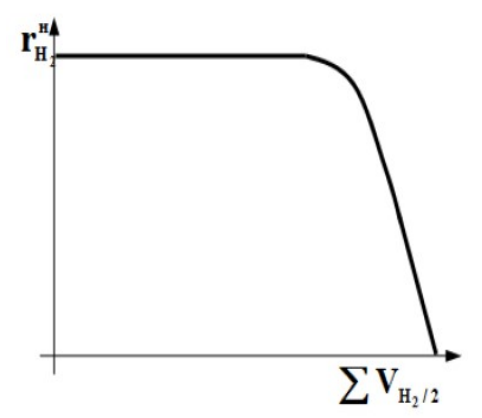

a

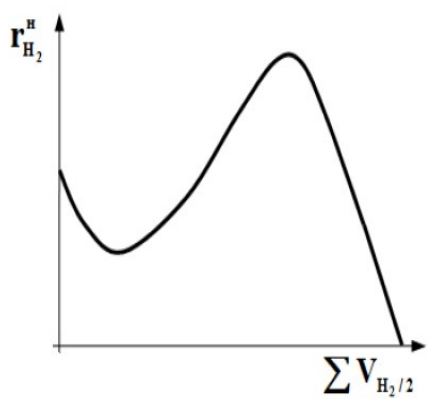

$\mathrm{b}$

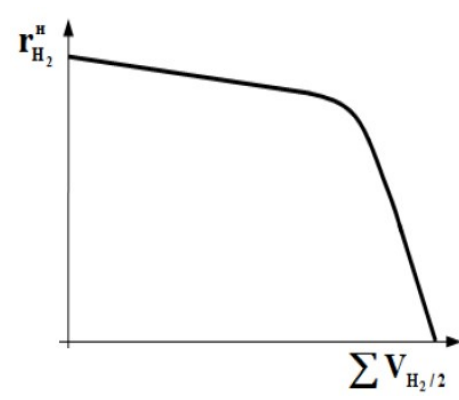

Fig.-1: Characteristic Dependences of Absorption Rates on the Amount of reacted Hydrogen in Liquid-phase Hydrogenation Reactions: a - Hydrogenation Mechanism; b - Condensation Mechanism; c - Hydrogenation Mechanism with Catalyst Deactivation

\section{Catalysts on the Base of Nickel}

Most studies of the reduction of nitro compounds, as shown by the analysis of patents and literature data, are carried out using nickel catalysts. ${ }^{1,10,15,20,21-26}$ The most common catalyst for the reduction of various objects, including nitro compounds, is Raney nickel. Skeletal nickel catalyst was developed by M. Raney in 1924-1925. It is obtained by leaching aluminum from aluminum-nickel alloys with different contents of these metals. With increasing nickel content in the initial alloy, the size of the crystals and the rate of leaching decrease. Nickel and copper catalytic systems are much more common and effective catalysts in industrial processes than catalyst systems based on noble metals. ${ }^{4,26,27}$ The advantages of skeletal catalysts are determined by the metal base and are in their mechanical strength, improved heat transfer, relatively low cost. The main technological disadvantages in the use of skeletal catalysts are reduced to the necessity of processing synthesis waste, possible deactivation of the catalyst both during its operation and during reactor loading, and its pyrophoricity. ${ }^{28,29}$

Fig.-2a shows an enlarged SEM image of a Raney nickel in which small cracks within 1-100 nm wide are observed inside the crystals, due to which the surface area increases. ${ }^{25}$ Figure-2b demonstrates the SEM of a skeletal nickel hydrogenation catalyst with well-fixed crystals $1-50 \mathrm{~m}$ in size.

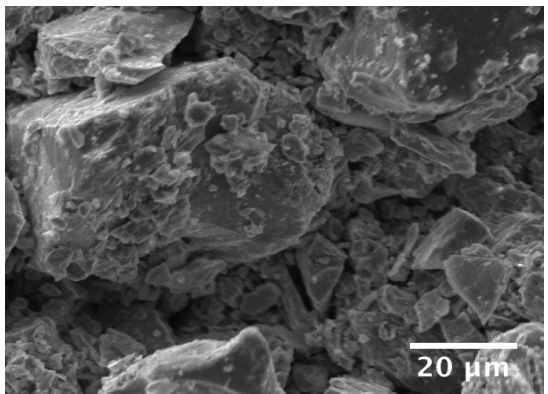

a

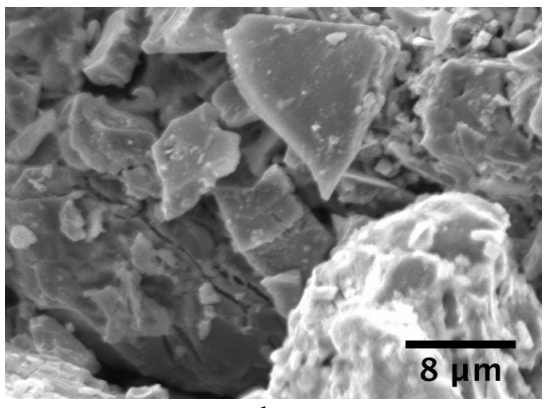

b

Fig.-2: Raney Nickel SEM Images: a-Enlarged SEM Image; b- Nickel Hydrogenation Catalyst ${ }^{25}$ 
RASĀYAN J. Chem.

The magnitude of nickel crystals depends on the leaching temperature, for each hydrogenated compound there is an optimal crystal size, which, for example, for the reduction of nitrobenzene is $5.9 \mathrm{~nm} .{ }^{30}$ The addition of vanadium and copper makes the catalyst more selective, prevents the hydrogenation of the nucleus. Typically, skeletal catalysts operate at atmospheric pressure; in turn, an increase in pressure significantly increases the reaction rate..$^{21,22,30,31}$

Along with Raney nickel other nickel-based catalysts are used, for example, nickel black, nickel catalysts on the different carriers (supports): $\mathrm{Ni} / \mathrm{Al}_{2} \mathrm{O}_{3}, \mathrm{Ni} / \mathrm{C}, \mathrm{Ni} / \mathrm{kieselguhr}, \mathrm{Ni} / \mathrm{SiO}_{2}, \mathrm{Ni} / \mathrm{ZnO}, \mathrm{Ni} / \mathrm{MgO}, \mathrm{Ni}-$ $\mathrm{Cr}_{2} \mathrm{O}_{3} / \mathrm{C}^{24,25,28,31-34}$

It was experimentally proved that the activity of a nickel catalyst is determined by the surface structure on which crystallites with an interplanar spacing are present: $5.6 \AA$; for skeletal nickel, peaks $2 \theta=540$ and $2 \theta=430$ correspond to similar crystallites ${ }^{20,21,24}$ An analysis of X-ray diffraction data shows that with an increase in the concentration of supported nickel oxide from 4.7 to $23.2 \mathrm{wt} . \%$, the size of coherent scattering regions (CSR) increases from 70 to $180 \AA$, and the degree of crystallinity of the supported oxide also increases. After reduction of the catalyst with hydrogen under the selected conditions, the characteristic peaks responsible for nickel oxide become insignificant, reflections responsible for metallic nickel appear. During the reduction of the $\mathrm{NiO} / \mathrm{SiO}_{2}$ samples studied, according to the X-ray diffraction patterns (Fig.-3a,b), 70\% of the deposited oxide goes into metallic nickel with structural properties characteristic of the active surface. ${ }^{24}$ The character of the distribution of elements on the surface of supported nickel catalysts on silica gel can be judged from the data of X-ray diffraction (Fig.-3a,b) and SEM (Fig.-3c)..$^{20,21,24}$

The hydrogenation of m-dinitrobenzene to m-phenylenediamine on bimetallic Ni-Pt/C catalysts was studied and a high hydrogenation rate and an almost $100 \%$ selectivity for $\mathrm{m}$-phenylenediamine were shown. ${ }^{35}$ The hydrogenation efficiency of bimetallic catalysts is higher than that of monometallic nickel catalysts. XRD and XPS data prove that the bulk of nickel in the monometallic catalyst is in the form of $\mathrm{Ni}^{2+}$, while the addition of platinum to nickel stabilizes the state of $\mathrm{NiO}$.

\section{Catalysts on the Base of $\mathrm{Fe}$}

In recent years, the attention of researchers has increasingly been attracted to the study of the reduction of organic compounds with various functional groups in the presence of iron-containing catalyst systems to decrease the cost of catalysts and less use of expensive noble metal catalysts. ${ }^{36-40}$

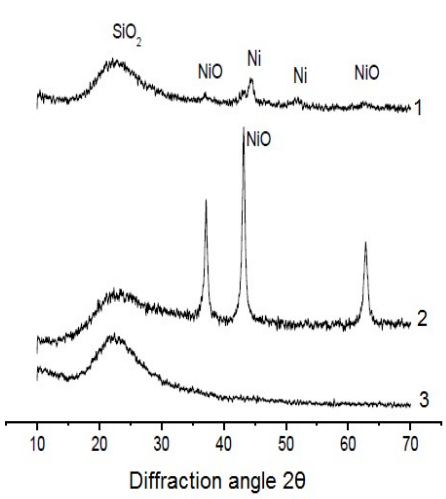

a

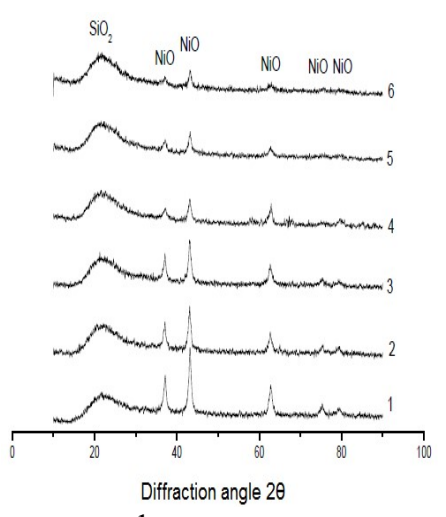

b

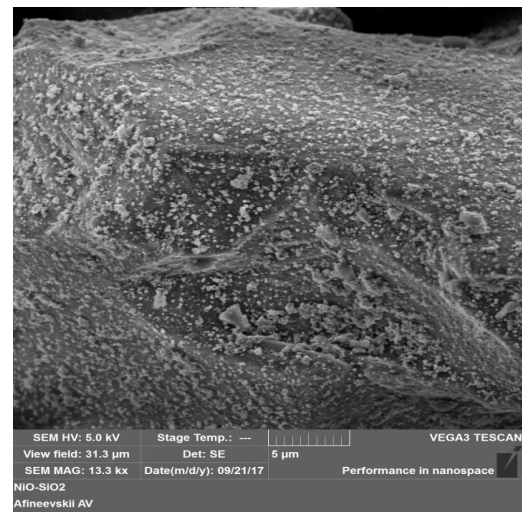

$\mathrm{c}$

Fig-3: X-ray Diffraction Patterns of the Catalysts (a, b): (a) 1 - Pure Silica Gel; 2- 23.2 wt.\% Deposited Nickel (in the form of oxide); 3 - Reduced Catalyst, 11 wt.\% of deposited Metallic Nickel; (b) Deposited oxide Nickel on Silica Gel, with a concentration of wt. \%: 1-11; 2-10; 3-9; 4-5; 5-4; 6-0.6; (c) SEM Image of a supported Nickel Catalyst $^{24}$

Of particular interest are Fe nanoparticles and their oxides, as well as bimetallic particles based on them. This is due to the prevalence of $\mathrm{Fe}$ in the earth's crust, low cost, non-toxicity. Also, iron-containing catalysts can exhibit magnetic properties. Due to its pronounced magnetic properties, $\mathrm{Fe}_{3} \mathrm{O}_{4}$ is most often 
RASĀYAN J. Chem.

Vol. 14 | No. 2 |1223-1229| April - June | 2021

used as a carrier for the preparation of supported catalysts, as well as independent catalytically active particles. In most cases, the precipitation method is used to obtain magnetite. ${ }^{41}$

The selective reduction of various nitroarenes having functional groups (halogen, olefin, carboxylic acid, amines, heterocyclic fragments, ketone, nitrile, hydroxy, ester) to corresponding aniline derivatives by transferring hydrogen on an iron-containing catalyst is described. ${ }^{42} \mathrm{~A}$ fairly easy method of preparation of iron pyrite $\left(\mathrm{FeS}_{2}\right)$ nanocrystals with the application of nano-needle iron oxyhydroxide as a precursor was proposed. For the preparation of the catalyst, $\beta-\mathrm{FeOOH}$ nanorods were applied as an iron precursor. The authors synthesized pyrite nanomaterial, which demonstrated good efficiency in the process of hydrogenation of nitroarenes to anilines. The yields of amines ranged from 67 to $99 \%$ at $100 \%$ selectivity. The supported catalysts of $8 \% \mathrm{Fe}_{2} \mathrm{O}_{3} / \mathrm{C}$ for selective reduction of nitrobenzene were prepared. ${ }^{43}$ Hydrazine hydrate was used as a source of hydrogen. When carrying out the reactions under mild conditions (atmospheric pressure and $60^{\circ} \mathrm{C}$ ), during the reaction time of 90 minutes, $100 \%$ selectivity of aniline formation at $95 \%$ nitrobenzene conversion was obtained.

The combination of two types of metals in catalysts can lead to the formation of solid solutions of Fe-Me $(\mathrm{Me}-\mathrm{Ni}, \mathrm{Pd}, \mathrm{Pt}, \mathrm{Ru})$ and, as a result, to a change in the catalytic properties of monometallic ironcontaining catalysts. ${ }^{44,45}$ The Ru catalyst with a $15 \%$ iron addition deposited on carbon and tested in the liquid-phase hydrogenation of nitro compounds was synthesized. ${ }^{46}$ The Ru-Fe/C catalyst obtained by stepwise impregnation, in comparison with the $\mathrm{Ru} / \mathrm{C}$ monometallic catalyst, exhibits higher catalytic activity, selectivity and high stability (up to 140 hours of the experiment) in liquid-phase hydrogenation of ortho-chloronitrobenzene (o-CNB) to ortho-chloraniline (o-CAN). The conversion of orthochloronitrobenzene (o-CNB) to the corresponding amine was $99.7 \%$, the selectivity on the o-CAN production was $98.7 \%$. Figure-4 shows the XPS spectrum of a freshly prepared $\mathrm{Ru}-\mathrm{Fe} / \mathrm{C}$ catalyst. The energy level of $\mathrm{Ru} 3 \mathrm{~d}_{3} / 2$, close to $\mathrm{C}^{1 \mathrm{~s}}$ (about $284 \mathrm{eV}$ ) was not observed. ${ }^{47,48}$ The presence of elementary $\mathrm{Ru}$ on the surface of the carrier is established, which corresponds to the binding energy of $\mathrm{Ru} 3 \mathrm{~d}_{5} / 2$ (BE) of $280.6 \mathrm{eV}$, and relative to the standard peak of $\mathrm{Ru}(281 \mathrm{eV})$ negatively shifted by $0.4 \mathrm{eV}$. The energy level of $\mathrm{Fe} 2 \mathrm{p}_{3 / 2}$ in the $\mathrm{Ru}-\mathrm{Fe} / \mathrm{C}$ catalyst $(\mathrm{BE}$ value is $711.1 \mathrm{eV}$ ) indicates that the Fe element in the sample exists in the form of $\mathrm{Fe}_{3} \mathrm{O}_{4}$, and its $\mathrm{BE}$ value is positively shifted by $0.6 \mathrm{eV}$ relative to the standard peak $\mathrm{Fe}_{3} \mathrm{O}_{4}(710.5 \mathrm{eV})$. This may be because $\mathrm{Fe}_{3} \mathrm{O}_{4}$ with electron-donating properties transfers some electrons to metallic $\mathrm{Ru}$, transforming $\mathrm{Fe}_{3} \mathrm{O}_{4}$ in the $\mathrm{Ru}-\mathrm{Fe} / \mathrm{C}$ catalyst into an electron acceptor state, thereby enhancing the electron-enriched $\mathrm{Ru}$ state.

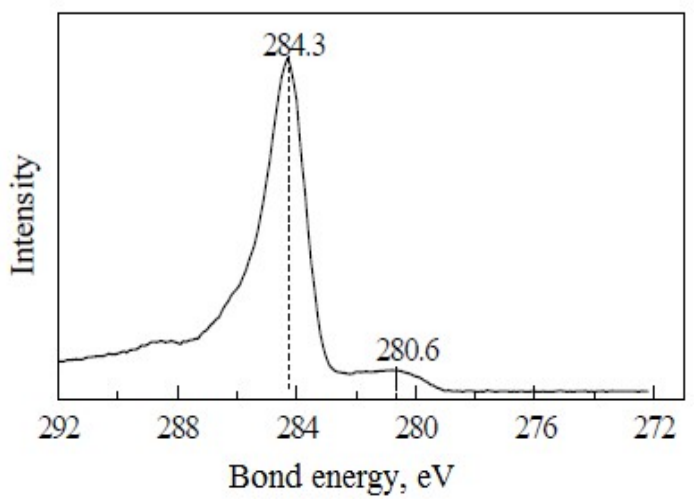

a

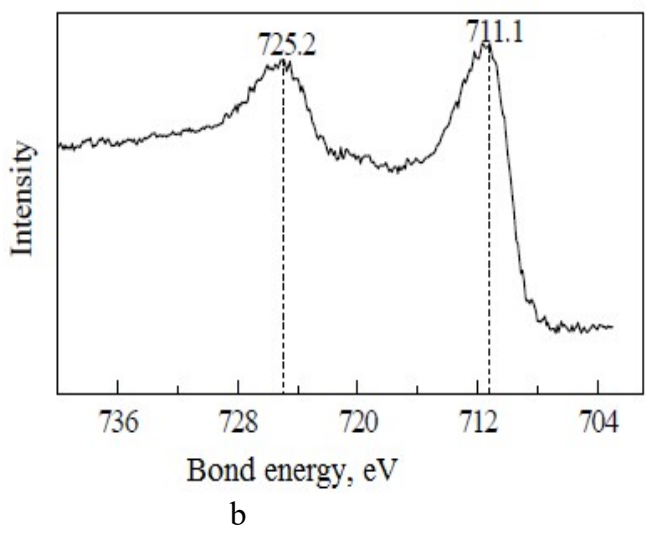

Fig.-4: XPS Spectra: (a) Ru 3d, (b) Fe 2p in Ru-Fe/C Catalyst ${ }^{46}$

It was shown that the addition of Pd to a supported monometallic Fe sample reduces the temperature of reduction of iron oxide phases by hydrogen to $400{ }^{\circ} \mathrm{C}$ and the formation of a $\mathrm{Pd}_{\mathrm{x}} \mathrm{Fe}_{1-\mathrm{x}}$ solid solution. ${ }^{44,49}$ The ratio of metals in Fe-Pd catalysts has a significant effect on the reducing ability of the samples. The Mössbauer spectroscopy of the $2 \mathrm{Fe}-2 \mathrm{Pd}$ sample (wt.\%) indicates the presence of metallic $\alpha$-Fe, an alloy of $\mathrm{Pd}_{x} \mathrm{Fe}$ and $\mathrm{Fe}^{2+}$ in the sample, reduced at $400{ }^{\circ} \mathrm{C}$. With an increase in the $\mathrm{Fe}: \mathrm{Pd}$ molar ratio to $5: 1$, the content of metallic iron particles increases. At the same time, when this ratio is $1: 1$, the amount of the $\mathrm{Pd}_{\mathrm{x}} \mathrm{Fe}$ alloy increases, while the number of $\mathrm{Pd}^{+}$centers decreases sharply. ${ }^{49}$ 
RASĀYAN J. Chem.

Vol. 14 | No. 2 |1223-1229| April - June | 2021

The $\mathrm{Pd}-\mathrm{Fe} / \mathrm{SiO}_{2}$ samples $\left(\mathrm{S}_{\text {specific }}=291 \mathrm{~m}^{2} / \mathrm{g}\right.$ ) obtained by co-impregnation with $\mathrm{H}_{2} \mathrm{PdCl}_{4}$ and $\mathrm{Fe}\left(\mathrm{NO}_{3}\right)_{3}$ solutions were studied using the Thermally Programmed Reduction- $\mathrm{H}_{2}\left(\mathrm{TPR}-\mathrm{H}_{2}\right)$ method (Fig.-5). ${ }^{44}$

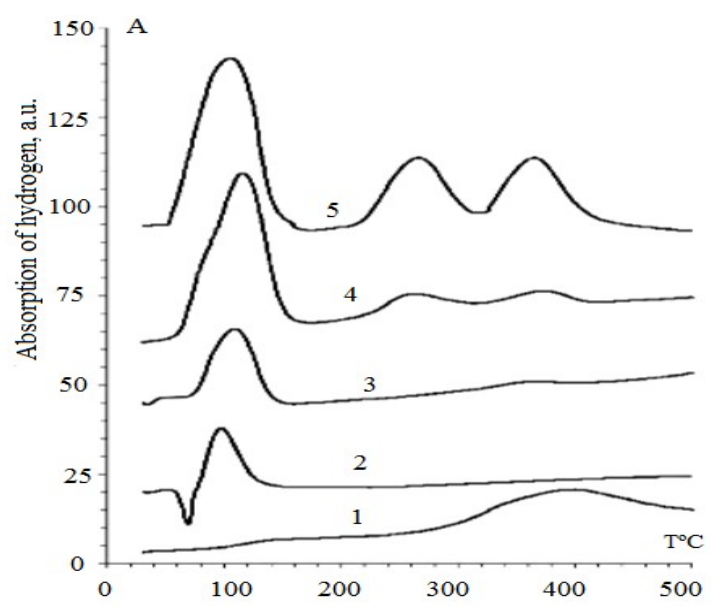

Fig.-5:TPR- $\mathrm{H}_{2}$ Curves of Samples calcined at $500^{\circ} \mathrm{C}$ : (1) $8 \mathrm{Fe} / \mathrm{SiO}_{2}$, (2) 5\% Pd / $\mathrm{SiO}_{2}$, (3) 5\% Pd-1\% Fe / $\mathrm{SiO}_{2}$, (4) $5 \% \mathrm{Pd}-8 \% \mathrm{Fe} / \mathrm{SiO}_{2},(5) 5 \% \mathrm{Pd}-20 \% \mathrm{Fe} / \mathrm{SiO}_{2}{ }^{44}$

It was shown that the reduction of a monometallic $5 \mathrm{Pd} / \mathrm{SiO}_{2}$ sample occurs in two stages in the temperature range of $50-150{ }^{\circ} \mathrm{C}$. The peak at $50-70{ }^{\circ} \mathrm{C}$ corresponds to the desorption of hydrogen from $\beta$ $\mathrm{PdH}$ obtained by the reduction of palladium oxide weakly bound to the carrier. At $90-150^{\circ} \mathrm{C}, \mathrm{PdO}$ is reduced to $\mathrm{Pd}^{0}$. The $8 \mathrm{Fe} / \mathrm{SiO}_{2}$ monometallic iron sample is reduced in a wide temperature range of 300 $500{ }^{\circ} \mathrm{C}$. The reduction of bimetallic samples starts at $100^{\circ} \mathrm{C}$ and ends at $300^{\circ} \mathrm{C}$, but there is a shift in the $\mathrm{PdO}$ reduction profile to a region of elevated temperatures, probably associated with the reduction of $\mathrm{Pd}_{\mathrm{x}} \mathrm{Fe}_{\mathrm{y}} \mathrm{O}$ particles. For bimetallic samples, there is no peak characteristic of $\beta-\mathrm{PdH}$.

Bimetallic $\mathrm{Fe}-\mathrm{Cu} / \mathrm{SiO}_{2}$ systems were proposed for the process of liquid-phase hydrogenation of $\mathrm{p}$ dinitrobenzene to $\mathrm{p}$-phenylenediamine..$^{50,51}$ The most active catalysts were synthesized by co-precipitation of metal precursors by urea hydrolysis. The strong interaction of $\mathrm{Fe}$ and $\mathrm{Cu}$ nanoparticles in catalysts associated with the preparation method facilitated the hydrogenation of $\mathrm{p}$-dinitrobenzene in the liquid phase with a selectivity higher than $80 \%$ for p-phenylenediamine.

The strong interaction of $\mathrm{Fe}$ and $\mathrm{Cu}$ nanoparticles in the catalysts, due to the synthesis method, promotes the process of effective hydrogenation of $\mathrm{p}$-dinitrobenzene in the liquid phase. The highest selectivity (89\%) for p-phenylenediamine and $100 \%$ conversion of $\mathrm{p}$-dinitrobenzene at $\mathrm{T}=145-180^{\circ} \mathrm{C}, \mathrm{P}_{\mathrm{H} 2}=1.3$ MPa was achieved on catalysts containing $7 \%$ iron and $3 \%$ copper, which were obtained by coprecipitation with further calcination at $300^{\circ} \mathrm{C} .^{51}$

\section{CONCLUSION}

The researches of hydrogenation reactions of aromatic nitro compounds to the corresponding amines on nickel and iron catalysts are described. The advantages of skeletal catalysts are determined by the metal base and are in their mechanical strength, improved heat transfer, relatively low cost. The main technological disadvantages in the use of skeletal catalysts are reduced to the necessity of processing synthesis waste, possible deactivation of the catalyst both during its operation and during reactor loading, and its pyrophoricity. In recent years, the attention of researchers has increasingly been attracted to the study of the reduction of organic compounds with various functional groups in the presence of ironcontaining catalyst systems to decrease the cost of catalysts and less use of expensive noble metal catalysts. The combination of two types of metals in catalysts can lead to the formation of solid solutions of Fe-Me ( $\mathrm{Me}-\mathrm{Ni}, \mathrm{Pd}, \mathrm{Pt}, \mathrm{Ru})$ and, as a result, to a change in the catalytic properties of monometallic iron-containing catalysts.

\section{REFERENCES}

1. I. Karamé (Eds.), Hydrogenation, Lebanese University, Lebanon (2012)

2. Y.A. Aubakirov and L.R. Sassykova, Selective Catalytic Reduction of Aromatic Nitro Compounds and Hydrocarbons: Monograph, Qazaq University, Almaty, p.9-32(2018) 
RASĀYAN J. Chem.

Vol. 14 | No. 2 |1223-1229| April - June | 2021

3. L. R. Sassykova, Y. A. Aubakirov, S. Sendilvelan, Zh. Kh. Tashmukhambetova, N. K. Zhakirova, M. F. Faizullaeva, A. A. Batyrbayeva, R. G. Ryskaliyeva, B. B. Tyussyupova and T. S. Abildin, Oriental Journal of Chemistry, 35(1), 22(2019), DOI:10.13005/ojc/350103

4. L. Petrov, K. Kumbilieva and N. Kirkov, Applied Catalysis, 59(1),31(1990), DOI:10.1016/S01669834(00)82185-5

5. H. Rojas, G. Borda, P. Reyes, M. Brijaldo and J. Valencia, Journal of the Chilean Chemical Society, 56(3), 793(2011), DOI:10.4067/S0717-97072011000300016

6. I.I. Obraztsova, N.K. Eremenko and G.Y. Simenyuk, Solid Fuel Chemistry, 46(6), 364(2012), DOI: $10.3103 / \mathrm{S} 0361521912060109$

7. P. Sangeetha, K. Shanthi, Rao Rama K.S., B. Viswanathan and P. Selvam, Applied Catalysis A: General, 353(2), 160(2009), DOI: 10.1016/j.apcata.2008.10.044

8. L. Sassykova, Y. Aubakirov, Chiang Mai Journal of Science, 45(1), 474(2018)

9. D. V. Sokolsky, A. A. Tsoi and V. P. Shmonina, Patent SU 199902 A1(1967)

10. Y.A. Aubakirov, L.R. Sassykova, Zh.Kh. Tashmukhambetova, S.Y. Karymbayev, S. Sendilvelan, M. Zharkyn, A.K. Zhussupova, A.A. Batyrbayeva and Sh.A. Kayrdynov, International Journal of Biology and Chemistry, 11(2), 89(2018), DOI:10.26577/ijbch-2018-2-326

11. Y.E. Romanenko, A.A. Merkin and O.V. Lefedova, Kinetics and Catalysis, 57(2), 212(2016), DOI: $10.7868 / \mathrm{s} 0453881116020118$

12. L. R. Sassykova, S. Sendilvelan, U. N. Otzhan, G. K. Vassilina, A. S. Zhumakanova, Z. T. Mataeva and M. B. Amangeldi, News of the National Academy of Sciences of the Republic of Kazakhstan, Series of Geology and Technical Sciences, 428(2), 18(2018)

13. Y. Aubakirov, L. Sassykova, S.Subramanian, K.Bhaskar, U.Otzhan, M. Amangeldi, T. Abildin, A.Zhumakanova, A.Zhussupova and M.Zharkyn, Journal of Chemical Technology and Metallurgy, 54(3), 522(2019)

14. M. Turakova, T. Salmi, K. Eranen, J. Warna, D.Murzin and M.Kralik, Applied Catalysis A: General, 499, 66(2015), DOI:10.1016/j.apcata.2015.04.002

15. L. Sassykova, U. Otzhan and A. Kurmansitova, Revue Roumaine de Chimie, 64(7), 561(2019), DOI: $10.33224 /$ rrch.2019.64.7.02

16. V. P. Shmonina, Proceedings of the Institute of Chemical Sciences of the Kazakh SSR, Kinetics and Catalysis, Alma-Ata, 14, 78-105(1966)

17. S. Galvagno, A. Donato, G. Neri, R. Pietropaolo and Z. Poltarzewski, Journal of Molecular Catalysis, 42(3), 379(1987), DOI:10.1016/0304-5102(87)85014-9

18. L.R. Sasykova, News of MS-AS of RK, Ser.Chem, 6, 50(1996)

19. J. Relvas, R. Andrade, F. G. Freire, F. Lemos, P. Araújo, M. J. Pinho, C. P. Nunes and F. R. Ribeiro, Catalysis Today, 133-135, 828(2008)

20. M.V. Lukin, D.A.Prozorov, M.V.Ulitin and Y.A.Vdovin, Kinetics and Catalysis, 54(4), 412(2013), DOI: $10.7868 / \mathrm{s} 0453881113040102$

21. A. F. Afineevskii, M. V. Lukin and D. A. Prozorov, Russian Journal of General Chemistry, 88(9), 1976(2018), DOI: $10.1134 / \mathrm{s} 1070363218090396$

22. V. Pandarus, R. Ciriminna, F. Béland and M. Pagliaro, Catalysis Science \& Technology, 1(9), 1616(2011), DOI:10.1039/c1 cy00097g

23. M. D. Navalikhina and O. V. Krylov, Russian Chemical Reviews, 67(7), 587(1998)

24. D. A. Prozorov, Adsorption and Catalytic Properties of Nickel in Reactions of Liquid Phase Hydrogenization, Dissertation of Dr. of Chem.Sci., Nizhny Novgorod, Russia (2019)

25. https://en.wikipedia.org/wiki/Raney_nickel

26. M.A. Kipnis, N.R. Gazimzyanov, A.I. Aleshin and V.S. Agoronov, Patent RF 2102145(1998)

27. L. Zhao, J. Chen and J. Zhang, Journal of Molecular Catalysis A: Chemical, 246(1-2), 140(2006), DOI:10.1016/j.molcata.2005.11.003

28. D.V. Sokolsky, Hydrogenation in solutions, Nauka, Alma-Ata, 1979

29. L. Yingxin, Ch. Jixiang and Zh.Jiyan, Chinese Journal of Chemical Engineering, 15(1), 63(2007), DOI: $10.1016 / \mathrm{s} 1004-9541(07) 60034-2$ 
30. B.M. Bogoslovsky, Skeletal catalysts, their properties and applications in organic chemistry, Goskhimizdat, Moscow, Russia, 10-24, 100 (1957)

31. A. A. Gorlov, Physico-chemical study of the preparation and immobilization of anestezin in nanoreactors and nanocontainers based on sulfonated network polymers, $\mathrm{Ph}$. D. Thesis, Kemerovo, Russia (2016)

32. J. Dulle, S. Nemeth, E.V. Skorb, T. Irrgang, J. Senker, R. Kempe and D.V. Andreeva, Advanced Functional Materials, 22(15), 3128(2012)

33. U. Dahlborg, C. M. Bao, M. Calvo-Dahlborg, F. Devred and B. E. Nieuwenhuys, Journal of Materials Science, 44(17), 4653(2009), DOI:10.1007/s10853-009-3712-4

34. H. Hu, M. Qiao, S. Wang, K.Fan, H.Li, B. Zong and X.Zhang, Journal of Catalysis, 221(2), 612(2004), DOI:10.1016/j.jcat.2003.09.027

35. M.M. Telkar, J.M. Nadgeri, C.V. Rode, and R.V. Chaudhari, Applied Catalysis A: General, 295(1), 23(2005), DOI:10.1016/j.apcata.2005.07.050

36. M. G. Meiramov, Solid Fuel Chemistry, 48(2), 123(2014)

37. M. Shokouhimehr, Catalysts, 5(2), 534(2015), DOI:10.3390/catal5020534

38. M. Tulepov, Z. Mansurov, L. Sassykova, D. Baiseitov, O. Dalelhanuly, Zh. Ualiev, Sh. Gabdrashova and Zh. Kudyarova, Journal of Chemical Technology and Metallurgy, 54(3), 531(2019)

39. D. A. Baiseitov, Sh. E. Gabdrashova, A. N. Magazova, O. Dalelkhanuly, Zh. B. Kudyarova, M. I. Tulepov, L. R. Sassykova and Z. A. Mansurov, International Journal of Chemical Science, 14(1), 244(2016)

40. Sh.E. Gabdrashova, N.M. Rakhova, I.O. Pustovalov, Zh. Elemesova, M.I. Tulepov, M.A. Korchagin, L.R. Sassykova, S. Sendilvelan and D.A. Baiseitov, Rasayan Journal of Chemistry, 11(1), 324(2018), DOI: 10.7324/RJC.2018.1112017

41. E. Yuan, G. Wu, W. Dai, N. Guan and L. Li, Catalysis Science \& Technology, 7(14), 3036(2017), DOI: $10.1039 / \mathrm{c} 7 \mathrm{cy} 00724 \mathrm{~h}$

42. M. Adhikari, A.Singh, E.Echeverria, D.N. McIlroy and Y.Vasquez, ACS Omega, 5(23), 14104(2020), DOI:10.1021/acsomega.0c01637

43. O. Beswick, I. Yuranov, D. T.L. Alexander and L. Kiwi-Minsker, Catalysis Today, 249, 45(2015), DOI: $10.1016 /$ j.cattod.2015.01.023

44. I. A. Witońska, M. J. Walock, M. Binczarski, M. Lesiak, A. V. Stanishevsky and S. Karski, Journal of Molecular Catalysis A: Chemical, 393, 248(2014)

45. L. R. Sassykova, Chemical and Biochemical Engineering Quarterly, 31(4), 447(2017), DOI: $10.15255 /$ CABEQ.2016.959

46. X. Xu, A. Chen, Li Zhou, X. Li, H. Gu and X. Yan, Chinese Journal of Catalysis (Chinese Version), 34(2), 391(2014), DOI:10.3724/sp.j.1088.2013.20959

47. S. Zhao, H. Liang, Y. Zhou, Catalysis Communications, 8(9), 1305(2007)

48. J. H. Deshmukh and M. N. Deshpande, Rasayan Journal of Chemistry, 4(2), 472(2011)

49. M. Nimz, G. Lietz and J. Volter, Catalysis Letters, 1(4), 93(1988)

50. A. A. Shesterkina, E. V. Shuvalova, O. A. Kirichenko, A. A. Strelkova, V. D. Nissenbaum, G. I. Kapustin and L. M. Kustov, Russian Journal of Physical Chemistry A, 91(2), 201(2017)

51. A. A. Shesterkina, Synthesis and Research of Iron-containing Catalysts for Selective Hydrogenation of Triple Bonds and Nitro Groups, Ph. D. Thesis, Moscow, Russia (2018)

[RJC-6124/2020] 